Ethiopian Journal of Environmental Studies \& Management 7(6): 588 - 598, 2014.

ISSN:1998-0507

doi: http://dx.doi.org/10.4314/ejesm.v7i6.1

Submitted: April 06, 2014

Accepted: September 20, 2014

\title{
EFFECTIVENESS EVALUATION OF CONTINGENCY SUM AS A RISK MANAGEMENT TOOL FOR CONSTRUCTION PROJECTS IN NIGER DELTA, NIGERIA
}

\author{
OTALI, M. AND *ODESOLA, I.A. \\ Department of Building, Faculty of Environmental Studies, University of Uyo
}

\begin{abstract}
Construction managers in a bid to effectively manage risks prone projects have adopted several methods, one of which is contingency sum. This study aims at evaluating the effectiveness of contingency sum as a risk management tool for construction projects in Niger Delta region of Nigeria. The objectives are to establish the level of awareness and utilization of contingency estimating methods among construction stakeholders, evaluate their perceptions of the percentage allowed for contingency in construction projects and determine whether there is a relationship between initial project cost, cost overrun and percentage allowed for contingency. Structured questionnaire served as the research instrument and the data were analysed using simple percentage, mean score and correlation. The findings of the study show that the most used contingency estimating method in the region is traditional percentage and that the three most important factors that affect the sum or percentage allowed as contingency for projects are complexity of the project, experience of the estimator and location of the project. The percentage allowed for projects as contingency by consultants and contractors in this study ranges between 5- 20 while the average contingency allowed is 10.4 (\%). Furthermore, there is no relationship between initial project cost and the percentage allowed for contingency $(p=0.294>0.05)$.It was concluded that the contingencies allowed for projects in Niger Delta are based on the discretions of the consultants and contractors and not a function of the estimated contract value and it is not adequate. The study therefore recommends that contingency sum or percentage allowed should not be limited to complexity of the project, experience of the estimator, location of the project or the total contract sum but should be based on a comprehensive assessment of all factors that generate risk in each particular project.
\end{abstract}

Key Words: Construction project, Contingency sum, Evaluation, Management tool, Risk.

\section{Introduction}

The incidence of construction cost overrun in Nigeria has become a source of concern to the consultants and contractors. It has become so alarming that one keeps on wondering and questioning the reliability of the estimates. Because of the peculiarity of construction projects, some of the items are made provisional and some of the unforeseen and unidentified events that might emerge during the construction processes are taken care of through the use of some cost control and risk management tools such as the contingency sum. Having put these measures in place, one expects that the cost objective of the projects would be achieved. Contrary to expectations, issues of construction cost overruns are still on the increase. Abimbola (2000) pointed out that government, clients, contractors and other workers in the

*Corresponding Author: Odesola, I.A.

Email: isaacodesola@yahoo.co.uk 
construction industry are all interested in the cost of construction as it affects them directly or indirectly. Rafter (1990) opined that the delivery of any building project is usually hinged on cost, quality and time within all possible risks, therefore the stakeholders in the construction industry must exercise great care and skill both in design and construction of the project through constant check on cost. Effective management of construction cost is very vital in ensuring effective project delivery. Failure to deliver projects within the predetermined cost has several negative implications. According to Achuenu (1997), the prevalence of unbudgeted increase in cost in completion of building contract has far reaching implications to the clients and contractors in particular and construction industry in general. It was also pointed out by Achuenu (1999) that project delivery in Nigerian construction industry is largely characterized by abandonment and delay at various stages of completion and at sums much higher than the initial estimated cost. Achuenu and Gundiri (1998) also observed that almost all projects in Nigeria are completed at sum higher than the initial contract sums and clients can hardly rely upon this initial contract sums. These are also supported by Touran (2003) which stated that project cost overruns are common in construction.

Cost contingency is included within a budget estimate so that the budget represents the total financial commitment for the project sponsor. The estimation of cost contingency and its ultimate adequacy is of critical importance to projects, hence the need to evaluate the effectiveness of contingency sum as a construction risk management tool and also determine how it can be improved. Contingency has been defined as the amount of money needed above the estimate to reduce the risk over runs of project objectives to a level acceptable to the organization
(PMI, 2000).Risk is defined as events within the defined project scope that are unforeseen (Moselhi, 1997; Yeo, 1990), unknown (PMI, 2000), unexpected (Mak et al., 1998), unidentified (Levine, 1995) or undefined (Thompson and Perry, 1992). Various contingency estimating methods were also identified from literature. These include traditional percentage (Ahmad, 1992; Moselhi, 1997), method of moments (Yeo, 1990), Monte Carlo Simulation (Lorance and Wendling, 2001), Factor Rating (Joseph et al., 2012). Regression (Aibinu and Jagboro, 2002), Artificial Neural Networks (Chen and Hartman, 2000, Williams, 2003), Fuzzy sets (Pack et al., 1994), Influence diagrams (Diekmann and Featherman, 1998), and theory constraints (Leach, 2003). Others include artificial hierarchy process (Dey et al., 1994), tolerance in the specification, float in the schedule and money in the budget (CIRIA, 1996).

Ford (2002) held that there is no evidence of formal standardized models or prescriptive contingency management methods or advanced objective analysis tools directed at contingency management. The above statement was tested and confirmed to be true by Touran (2003) and Keith (2011). Cost contingency is an essential part of project cost estimating which in turn is the key stone of cost emergency and total cost management. A thorough integrated risk approach is essential in the process of estimating cost contingency (Buertey et al.,2012). The challenges for lack of basis for the determination and provision of adequate contingency results in cost overruns in the project, difficulty in contingency management, abandonment of project due to lack of adequate funds, a delay in the use of the project for downstream business or social benefit and characterization of construction industry as a high risk industry due to loan defaulting by contractors and clients (Buertey 
et al., 2012). Gunhan and Arditi (2007) posit that one of the simplest methods of estimating contingency margins for construction project is to consider a percentage of the estimated contract value such as $10 \%$ across the entire project commissioned by the owner which is derived from intuition, past experience and historical data. The allocation of small amount of contingency for projects may result in significant losses. On the other hand, high amount of contingency may decrease the chances of winning the contract.

The aim of this study is to evaluate the effectiveness of contingency sum as a risk management tool for construction projects in Niger Delta region of Nigeria. The objectives include establishment of the awareness and utilization of contingency estimating methods among construction stakeholders, evaluation of stakeholder's perception of contingency (\%) allowed for construction projects, evaluation of the relationship between initial project cost and percentage allowed for contingency and establishment of the relationship between cost overruns and contingencies $(\%)$ allowed.

\section{Methodology}

Data were collected using structured questionnaire designed and administered to stakeholders in the built environment in Niger Delta, Nigeria. A total of three hundred copies of questionnaire were administered at random to purposively sampled construction project stakeholders which include consultants and contractors. Two hundred and sixty copies of valid questionnaire were returned with the required set of data and were analysed to achieve the objectives of this study. Construction records on one hundred and twenty completed projects were collected through the questionnaire; showing initial contract sum, final contract sum and the percentage allowed for contingency for the various projects. The respondents in the questionnaire were also asked to provide information on the contingency estimating methods used, their awareness of contingency estimating methods and their level of use or application. Factors influencing the amount of the percentage allowed for contingency were identified from literature and previous studies. Data were collected on them on a five point scale of 5 , 4, 3, 2 and 1 and were assigned to the options of nil, low, moderate, high and very high.

\section{Data Analysis Techniques}

The techniques used for data analysis in this study include simple percentage, mean score and correlation. The simple percentage was used to compute the average percentages of cost overruns, contingency $\operatorname{sum}(\%)$ and the level of awareness and utilization of the various methods of estimating contingency. The mean score was used to analyse the perception of the stakeholders in the study area about the factors influencing the percentage allowed for contingency for effective project delivery and the correlation analysis was used to test the hypothesis which states that there is no significant relationship between the total project cost and the allowed contingency sums. There was also the need to test the hypothesis which states that there is no relationship between the percentage of cost overruns and the percentage of contingency sums allowed. In order to achieve this, correlation was used to analyse these sets of data.

\section{Result and Discussion}

Level of Awareness and Utilization of Contingency Estimating Methods among Construction Stakeholders

Table 1 shows that $96.2 \%$ of the respondents are aware of traditional percentage contingency estimating method while $76.9 \%$ of the respondents agreed that they have used the method before. $46.2 \%$ and 
$38.5 \%$ of the stakeholders agreed that they are aware of range estimating and individual risks respectively while $20 \%$ and $15 \%$ of the stakeholders indicated that they have used range estimating and individual risks respectively. The least used method among the evaluated contingency estimating methods is the artificial neural networks.

The analysis presented on Table 1 shows that these stakeholders are aware of other methods except Fussy Sets but many have decided to stick to the traditional percentage method probably because of its ease of use. This study revealed that the contingencies allowed for projects used in this study were based on traditional percentage. Results of analysis show that many of the projects suffered cost over runs and this is evidence that the traditional percentage method employed for the computation of contingency is not adequate. It is of great necessity for these stakeholders to try other methods, review and improve their knowledge base in this area of concern for effective project delivery.

This study agrees with Baccarini (2004) which stated that majority of the organizations used traditional percentage approach for estimating construction contingency. This research is also in agreement with Buertey et al. (2012) that concluded that most of the projects executed under study relied on the use of traditional percentage method for the estimation of cost contingency. It is also in consonance with Gunhan and Arditi (2007) which posit that one of the simplest methods of estimating contingency is to consider a percentage of the estimated contract value.

Table 1: Evaluation of the Level of Awareness and Utilisation of Contingency Estimating Methods among Construction Stakeholders

\begin{tabular}{llcccc}
\hline S/N & \multicolumn{1}{c}{$\begin{array}{c}\text { Contingency estimating } \\
\text { methods }\end{array}$} & $\begin{array}{c}\text { Level of } \\
\text { Awareness } \\
\text { (Number) }\end{array}$ & $\begin{array}{c}\text { Level of } \\
\text { Awareness (\%) }\end{array}$ & $\begin{array}{c}\text { Level of } \\
\text { Utilisation } \\
\text { (Number) }\end{array}$ & $\begin{array}{c}\text { Level of } \\
\text { Utilisation (\%) }\end{array}$ \\
\hline 1 & Traditional percentage & 250 & 96.20 & 200 & 76.9 \\
2 & Method of moments & 20 & 7.6 & - & - \\
3 & Factor rating & 30 & 11.5 & 10 & 3.8 \\
4 & Monte Carlo Simulation & 10 & 3.8 & - & - \\
5 & Individual risks & 100 & 38.5 & 15 & 5.7 \\
6 & Range estimating & 120 & 46.2 & 20 & - \\
7 & Regression analysis & 25 & 9.6 & - & 1.9 \\
8 & Artificial neural networks & 80 & 30.8 & 5 & - \\
9 & Fussy sets & - & - & - & - \\
10 & Controlled interval memory & 10 & 3.8 & - & - \\
11 & Influence diagrams & 20 & 7.6 & - & - \\
12 & Theory of constraints & 25 & 9.6 & - & - \\
13 & Analytical hierarchy process & 8 & 3 & 20 & 7.6 \\
14 & Deterministic estimation & 60 & 23 & & - \\
\hline
\end{tabular}

Stakeholders Perception of the Relative Effects of Factors Influencing the Percentage allowed for Contingency

The results of the analysis of stakeholders' perception on the considered factors show that the top four factors that affect contingency sum or the percentage allowed as contingency are complexity of the project, experience of the estimator, location of the project and total contract sum with their mean scores of 4.65, 4.46, 4.38 and 4.35 respectively. Table 2 shows that the least 
important factor that affects contingency sum or percentage is weather condition. This study reveals that the stakeholders under study don't pay attention to this factor while preparing estimates, hence their reason for rating it least. This further shows that majority of the consultants and contractors don't pay adequate attention to the effects of weather on the overall project performance. The implication of this is that construction projects in this region will suffer delay, cost overruns as experienced by the projects under study as well as total project abandonment.

Table 2 also shows that inflation rate is the second least factor that affects contingency sum or percentage. This indicates that majority of the consultants and contractors don't consider inflation as an important factor that affect contingency. It shows that they don't pay adequate attention to the unpredictable nature of the inflation rate in the Nigerian economy before forecasting or allowing any sum or percentage for contingency purpose. Therefore, there is a disconnection between their perception and the reality in the Nigerian construction market. In view of this, the factor may not be unconnected with the cost over runs experienced by the construction projects under study.

Table 2: Stakeholders Perception of the Relative Effects of Factors Influencing the Percentage allowed for Contingency

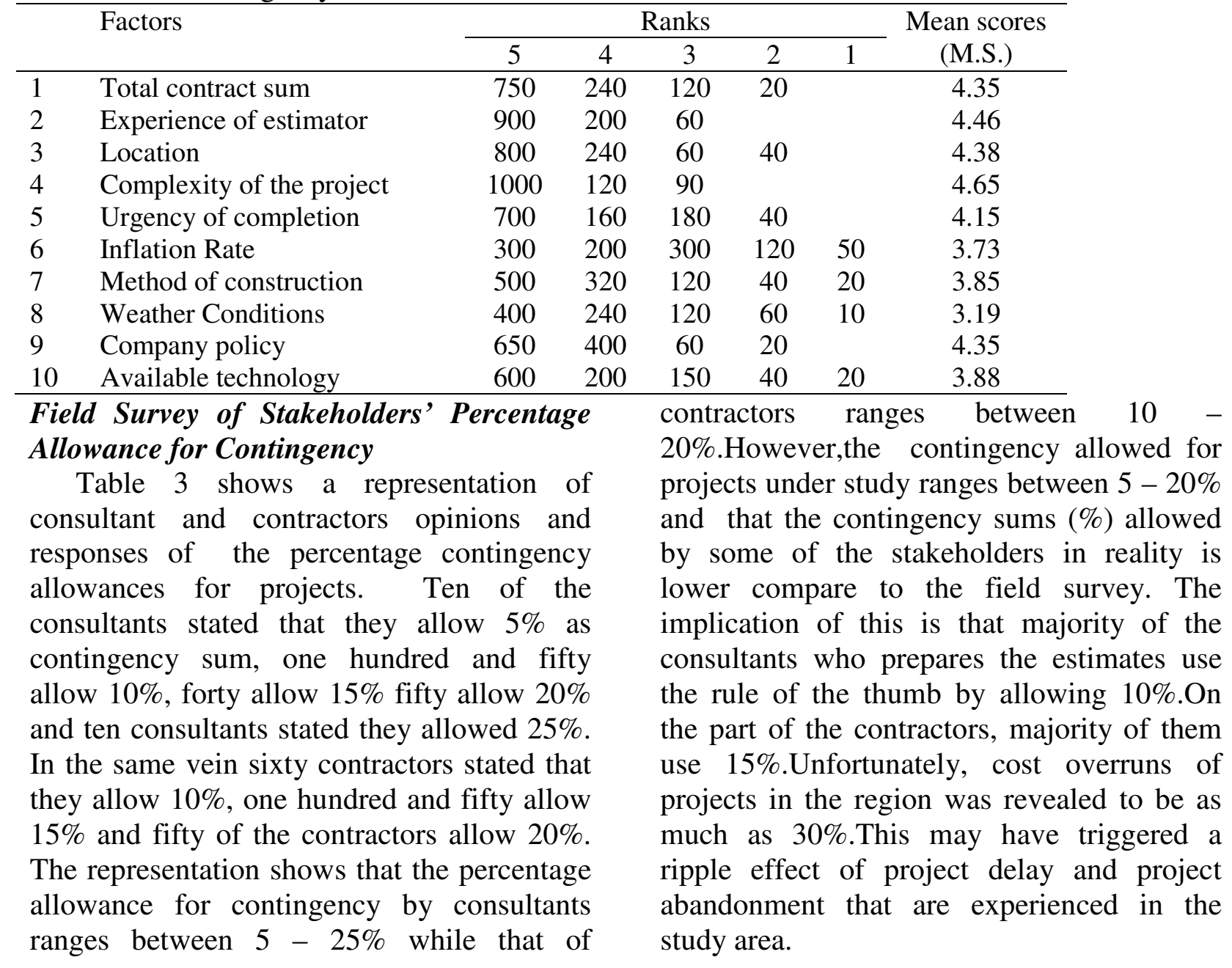


Effectiveness Evaluation of Contingency Sum as a Risk Management Tool................OTALI \& ODESOLA

Table 3: Field Survey of Stakeholders' Percentage Allowance for Contingency

\begin{tabular}{ccc}
\hline Percentage Allowed (\%) & $\begin{array}{l}\text { Number of Respondents } \\
\text { (Consultants) }\end{array}$ & $\begin{array}{l}\text { Number of Respondents } \\
\text { (Contractors) }\end{array}$ \\
\hline 5 & 10 & - \\
10 & 150 & 60 \\
15 & 40 & 150 \\
20 & 50 & 50 \\
25 & 10 & - \\
\hline
\end{tabular}

Comparison of Construction Cost Over Runs (\%) and Contingency Sum (\%)

Result of analysis shows that the average cost overruns is $11.8 \%$ while the average contingency $(\%)$ allowed for the projects is $10.4 \%$. This shows an increase of $1.4 \%$ that was not covered by the allowed contingency $(\%)$.It implies that the allowed contingency $(\%)$ is inadequate or ineffective by $1.4 \%$..This study reveals that the cost overruns experienced by the projects under study can be attributed to inadequacy in the contingency sum allowed and some other factors ranging from the experience of the estimator, the location of the projects, complexity of the projects, urgency of completion, weather conditions, method of construction ,available technology, company policy and inflation rate. Interviews with some of the stakeholders showed that some of the consultants did not have adequate knowledge of the location before allowing a particular percentage as contingency. Investigations in the course of this study also revealed that some of the contractors didn't have adequate knowledge of the projects locations before bidding for them. Another key factor most the stakeholders attributed to the cost overruns is the weather condition of the region. This has led to time overruns of many projects which in turns culminated to cost overruns, project delay and projects abandonment. This study is related to Baccarini (2004) which found that the average construction contingency was 5.24\% of the award contract value but the average value of contract variations was $9.92 \%$.

Evaluation of the Relationship Between Initial Project Cost and Contingency Allowance (\%)

It was found that there is no relationship between the initial project cost and the percentage allowed for contingency $(\mathrm{p}=$ $0.294>0.05$ ). This further validates that the consultants allow a particular percentage of the contract sum as contingency based on their discretion and past experience. Unfortunately, their discretions are not adequate enough for this purpose. It becomes significant and imperative for these stakeholders to consider the peculiarity and the uniqueness of each project before allowing a particular sum or percent as contingency. 
Table 4: Construction Project Costs and Contingency Sums (\%)

\begin{tabular}{|c|c|c|c|c|}
\hline $\mathbf{S} / \mathbf{N}$ & Initial Project cost & Final Project Cost & Cost over run (\%) & Contingency allowed (\%) \\
\hline 1 & $5,799,726$ & $6,495,693$ & 12 & 10 \\
\hline 2 & $6,521,314$ & $7,238,659$ & 11 & 10 \\
\hline 3 & $4,028,832$ & $4,592,869$ & 14 & 10 \\
\hline 4 & $40,540,213$ & $45,405,039$ & 12 & 10 \\
\hline 5 & $4,710,386$ & $5,416,944$ & 15 & 10 \\
\hline 6 & $5,126,120$ & $5,536,210$ & 8 & 10 \\
\hline 7 & $11,936,292$ & $13,368,647$ & 12 & 10 \\
\hline 8 & $12,750,000$ & $14,280,000$ & 12 & 10 \\
\hline 9 & $10,386,850$ & $11,010,061$ & 6 & 10 \\
\hline 10 & $12,850,000$ & $14,777,500$ & 15 & 10 \\
\hline 11 & $12,800,000$ & $14,720,000$ & 15 & 10 \\
\hline 12 & $10,784,160$ & $11,323,368$ & 5 & 10 \\
\hline 13 & $12,535,326$ & $13,036,739$ & 4 & 10 \\
\hline 14 & $12,750,000$ & $15,300,000$ & 20 & 10 \\
\hline 15 & $12,750,000$ & $14,535,000$ & 14 & 10 \\
\hline 16 & $12,750,000$ & $14,280,000$ & 12 & 10 \\
\hline 17 & $15,938,826$ & $19,126,591$ & 20 & 15 \\
\hline 18 & $13,149,393$ & $14,464,332$ & 10 & 8 \\
\hline 19 & $12,000,000$ & $12,960,000$ & 8 & 5 \\
\hline 20 & $11,936,800$ & $13,727,320$ & 15 & 10 \\
\hline 21 & $13,750,000$ & $14,850,000$ & 8 & 10 \\
\hline 22 & $4,201,494$ & $4,201,494$ & - & 5 \\
\hline 23 & $6,459,624$ & $6,459,624$ & - & 5 \\
\hline 24 & $5,182,513$ & $5,182,513$ & - & 5 \\
\hline 25 & $9,000,000$ & $9,450,000$ & 5 & 10 \\
\hline 26 & $12,404,660$ & $12,776,780$ & 3 & 5 \\
\hline 27 & $13,000,000$ & $13,650,000$ & 5 & 5 \\
\hline 28 & $13,500,000$ & $15,25,000$ & 15 & 10 \\
\hline 29 & $12,535,326$ & $13,788,859$ & 10 & 10 \\
\hline 30 & $14,208,074$ & $15,060,558$ & 6 & 5 \\
\hline 31 & $20,489,247$ & $25,611,559$ & 25 & 10 \\
\hline 32 & $9,000,500$ & $10,350,575$ & 15 & 10 \\
\hline 33 & $11,859,380$ & $11,859,380$ & & 5 \\
\hline 34 & $5,208,170$ & $5,364,415$ & 3 & 5 \\
\hline 35 & $9,000,000$ & $9,990,000$ & 11 & 10 \\
\hline 36 & $62,994,066$ & $74,332,998$ & 18 & 10 \\
\hline 37 & $13,500,000$ & $14,580,000$ & 8 & 10 \\
\hline 38 & $11,000,000$ & $11,550,000$ & 5 & 10 \\
\hline 39 & $13,542,894$ & $15,574,328$ & 15 & 10 \\
\hline 40 & $8,000,000$ & $8,000,000$ & - & 5 \\
\hline 41 & $9,700,000$ & $9,700,000$ & - & 5 \\
\hline 42 & $14,750,000$ & $15,487,500$ & 5 & 10 \\
\hline 43 & $248,728,679$ & $261,165,113$ & 5 & 10 \\
\hline 44 & $18,200,382$ & $18,564,390$ & 2 & 10 \\
\hline 45 & $8,328,787$ & $8,745,226$ & 5 & 10 \\
\hline 46 & $95,99,566$ & $9,983,549$ & 4 & 10 \\
\hline 47 & $10,918,643$ & $12,020,507$ & 10 & 10 \\
\hline 48 & $123,135,050$ & $129,291,803$ & 5 & 15 \\
\hline
\end{tabular}




\begin{tabular}{|c|c|c|c|c|}
\hline 49 & $3,675,186$ & $3,675,186$ & - & 5 \\
\hline 50 & $4,405,504$ & $4,493,614$ & 2 & 10 \\
\hline 51 & $1,512,967,031$ & $1,588,615,383$ & 5 & 10 \\
\hline 52 & $9,746,755$ & $9,746,755$ & - & 5 \\
\hline 53 & $14,250,000$ & $14,962,500$ & 5 & 10 \\
\hline 54 & $206,797,756$ & $248,157,307$ & 20 & 10 \\
\hline 55 & $55,415,967$ & $5,415,967$ & - & 5 \\
\hline 56 & $3,394,182$ & $3,394,182$ & - & 5 \\
\hline 57 & $13,750,000$ & $15,400,000$ & 12 & 10 \\
\hline 58 & $6,835,690$ & $6,972,404$ & 2 & 5 \\
\hline 59 & $63,292,947$ & $75,951,536$ & 20 & 15 \\
\hline 60 & $5,600,500$ & $5,600,500$ & - & 5 \\
\hline 61 & $4,120,747$ & $4,326,784$ & 5 & 10 \\
\hline 62 & $6,564,543$ & $7,549,224$ & 15 & 10 \\
\hline 63 & $7,468,195$ & $7,841,605$ & 5 & 12 \\
\hline 64 & $11,831,471$ & $13,014,618$ & 10 & 15 \\
\hline 65 & $12,676,876$ & $13,310,720$ & 5 & 15 \\
\hline 66 & \begin{tabular}{|l|}
$13,051,054$ \\
\end{tabular} & $16,313,818$ & 25 & 20 \\
\hline 67 & $13,092,006$ & $15,710,407$ & 20 & 20 \\
\hline 68 & $12,900,000$ & $14,835,000$ & 15 & 20 \\
\hline 69 & $10,000,000$ & $11,500,000$ & 15 & 10 \\
\hline 70 & $5,590,557$ & $6,708,668$ & 20 & 10 \\
\hline 71 & $32,508,973$ & $37,385,319$ & 15 & 10 \\
\hline 72 & $17,000,000$ & $21,250,000$ & 25 & 20 \\
\hline 73 & $15,250,000$ & $18,300,000$ & 20 & 15 \\
\hline 74 & $7,853,525$ & $9,031,554$ & 15 & 10 \\
\hline 75 & $6,744,228$ & $8,093,074$ & 20 & 10 \\
\hline 76 & $18,942,247$ & 2,3677,809 & 25 & 10 \\
\hline 77 & $18,349,766$ & $23,854,696$ & 30 & 20 \\
\hline 78 & $6,190,000$ & $7,428,000$ & 20 & 10 \\
\hline 79 & $10,750,000$ & $13,437,500$ & 25 & 15 \\
\hline 80 & $32,310,396$ & $38,772,475$ & 20 & 15 \\
\hline 81 & $32,360,192$ & $38,832,230$ & 20 & 10 \\
\hline 82 & $29,769,850$ & $37,212,313$ & 25 & 15 \\
\hline 83 & $7,706,463$ & $8,631,239$ & 12 & 10 \\
\hline 84 & $12,545,350$ & $14,427,153$ & 15 & 10 \\
\hline 85 & $8,821,542$ & $10,585,850$ & 20 & 10 \\
\hline 86 & $9,900,100$ & $11,385,115$ & 15 & 10 \\
\hline 87 & $11,950,200$ & $14,340,240$ & 20 & 15 \\
\hline 88 & $179,369,410$ & $206,274,822$ & 15 & 10 \\
\hline 89 & $9,250,382$ & $10,360,428$ & 12 & 10 \\
\hline 90 & $6,316,530$ & $7,264,010$ & 15 & 12 \\
\hline 91 & $13,755,600$ & $16,506,720$ & 20 & 15 \\
\hline 92 & $515,616,709$ & $618,740,051$ & 20 & 15 \\
\hline 93 & $248,019,440$ & $277,781,773$ & 12 & 10 \\
\hline 94 & $251,279,556$ & $326,663,423$ & 30 & 20 \\
\hline 95 & $200,000,000$ & $230,000,000$ & 15 & 10 \\
\hline 96 & $179,630,350$ & $215,556,420$ & 20 & 15 \\
\hline 97 & $791,729,412$ & $910,488,824$ & 15 & 10 \\
\hline 98 & $800,500,000$ & $1,000,625,000$ & 25 & 10 \\
\hline
\end{tabular}




\begin{tabular}{|l|l|l|c|c|}
\hline 99 & $421,921,500$ & $506,305,800$ & 20 & 15 \\
\hline 100 & $248,728,679$ & $286,037,981$ & 15 & 10 \\
\hline 101 & $179,470,500$ & $215,364,600$ & 20 & 10 \\
\hline 102 & $179,500,000$ & $201,152,000$ & 12 & 15 \\
\hline 103 & $180,800,000$ & $226,000,000$ & 25 & 5 \\
\hline 104 & $11,950,280$ & $14,101,330$ & 18 & 10 \\
\hline 105 & $5,468,195$ & $5,468,195$ & - & 5 \\
\hline 106 & $17,500,000$ & $18,200,000$ & 4 & 10 \\
\hline 107 & $4,270,515$ & $4,270,515$ & - & 10 \\
\hline 108 & $13,728,000$ & $14,414,400$ & 5 & 10 \\
\hline 109 & $5,323,607$ & $5,323,607$ & - & 10 \\
\hline 110 & $230,548,731$ & $276,658,477$ & 20 & 10 \\
\hline 111 & $12,360,713$ & $14,338,427$ & 16 & 10 \\
\hline 112 & $12,855,400$ & $14,655,156$ & 14 & 10 \\
\hline 113 & $9,248,922$ & $10,636,260$ & 15 & 10 \\
\hline 114 & $2,137,101$ & $2,137,101$ & - & 10 \\
\hline 115 & $797,861,864$ & $867,861,864$ & 8.8 & 10 \\
\hline 116 & $719,814,383$ & $806,192,109$ & 12 & 10 \\
\hline 117 & $12,277,730$ & $14,119,390$ & 15 & 10 \\
\hline 118 & $16,977,727$ & $18,505,722$ & 9 & 14 \\
\hline 119 & $12,829,437$ & $14,625,558$ & - & \\
\hline 120 & $7,825,180$ & $7,825,180$ & & \\
\hline
\end{tabular}

\section{Conclusion and Recommendations}

From the result of analysis, it was concluded that the most used method among the contingency estimating methods is traditional percentage. The study also established that the three most important factors that affect the sum or percentage to be allowed as contingency for projects are complexity of the project, experience of the estimator and location of the project respectively. It was also concluded that there is significant difference in the cost overruns $(\%)$ and the contingency (\%) allowed by the stakeholders. It was revealed that there is no relationship between the initial project cost and the allowed contingency (\%).The study shows that the percentage allowed by stakeholders in this region ranges between 5$25 \%$ while the projects under study in this region show that the percentage of cost over runs in Niger Delta region ranges between 3 - 30\%. It is important to note that the stakeholders should not limit themselves to traditional percentage method only but incorporate detail investigation and evaluation of contributing factors that lead to cost over runs. This gives them stronger knowledge base to decide the exact sum or percentage that should be added or allowed for effective risk management and better project performance.

In conclusion, the contingency (\%) allowed for project in this study are based on stakeholders' discretion and are not effective, hence the stakeholders should also apply other contingency estimating methods, review and improve their knowledge base for effective project performance. Contingency allowance should not be limited to complexity of the project, experience of the estimator, or the total contract sum but should be on a comprehensive assessment of all contributing factors that generate risk in each particular project. 
Effectiveness Evaluation of Contingency Sum as a Risk Management Tool.................TALI \& ODESOLA

\section{References}

Abimbola,R. (2000). Management Implication of Trends in Construction Cost in Nigeria from 1989 to 1999.Journal of the Nigerian Quantity Surveyors.PP30,35-40.

Achuenu,E. and Gundiri,F.B.(1998).Contract Price Escalation in Nigeria Building Industry. Journal of Environmental Sciences.2(1),pp10-15.

Achuenu,E. (1997). Elemental Cost Prediction of Public Building Projects in Nigeria. Seminar paper Presentation at the Department of Building, University of Jos.Pp1-20.

Achuenu,E. (1999). An Elemental Approach to the Evaluation and Modelling of Cost Overrun of Public Office Building Projects in Nigeria. Unpublished Ph.D Thesis (Construction Management) Department of Building, University of Jos.

Ahmad, I. (1992). Contingency Allocation: A computer-Aided Approach AACE Transactions, $28^{\text {th }}$ June $-1^{\text {st }}$ July, Orlando, F. 4. 1-7.

Aibinu, A. A. and Jagboro, G. D. (2002). The Effects of Construction Delays on Project Delivery in Nigerian Construction Industry. International Journal of Project Management, 20, 593-599.

Baccarini,D.(2004). Accuracy in Estimating Project Cost Construction Contingency-A statistical Analysis. Department of Construction Management, Curtin University of Technology, Western Australia, Australia.

Buertey, J.T.I., Abeere-Inga, E.,Adjei Kumi, T. (2012). Practical Application of Risk Management Techniques in Infrastructural Development: Proceedings of $1^{\text {st }}$ International Conference on Infrastructural Development in Africa at KNUST, Kumasi.

Chen, D. and Hartman, F. T. (2000). A Neural Network Approach to Risk Assessment and Contingency Allocation. AACE Transactions, $24-27^{\text {th }}$ June, Risk $07.01-$ 6.

Construction Industry Research and Information Association, (1996). Control of Risk. A
Guide to the Systematic Management of Risk from Construction. London: CIRIA.

Dey, P., Tabucanon, M. T. and Ogunlana, S. O. (1994). Planning for Project Control Through Risk Analysis. A Petroleum Pipe Laying Project. International Journal of Project Management, 12(1), 23-33.

Diekmann, J. E. and Featherman, W. D. (1998). Assessing Cost Uncertainty: Lessons from Environmental Restoration Projects. Journal of Construction Engineering and Management, 124(6), 445-451.

Ford,D. (2002). Achieving Multiple Project Objectives through Contingency Management. Journal of Construction Engineering and Management.128(1),3039.

Gunhan, S. and Arditi, D. (2007). Budgeting Owners Construction Contingency. ASCE Journal of Construction Engineering and Management vol 133,Issue 7,Pp 492-497.

Joseph, I. T. B., Emmanuel, A. I. and Theophilus, A. K. (2012). Project Cost Contingency Estimation in Ghana. An integrated Approach. Science Journal of Civil Engineering and Architecture.

Keith,R.M.(2011). A Risk Based Approach to Contingency Estimating in High way project Development, American Society of Civil.

Leach, L. P. (2003). Schedule and Cost Buffer Sizing. How to Account for the Bias Between Project Performance and Your Model. Project Management Journal, 34(2), 34-47.

Levine, H. (1995). Risk Management for Dummies. Managing Schedule Cost and Technical Risks and Contingency. PM Network, October, 30-32.

Lorance, R. B. and Wendling, R. V. (2001). Basic Techniques for Analysing and Presenting Cost Risk Analysis. Cost Engineering, 43(6): 25-31.

Mak, S., Wong, J. and Picken, D. (1998). The Effect on Contingency Allowances of Using Risk Analysis in Capital Cost Estimating. A Hong Kong Case Study. Construction Management and Economics, $16,615-619$. 
Moselhi, O. (1997). Risk Assessment and Contingency Estimating AACE Transactions, $13-16^{\text {th }}$ July, Dallas. D and RM/A 06.1-6.

Pack, J. H., Lee, Y. W. and Ock, J. H. (1994). Pricing Construction Risk. Fuzzy Set Application. Journal of Construction Engineering and Management, 119(4), 743-756.

Project Management Institute (2000). A Guide to the Project Management Body of Knowledge. Upper Darby P.A.

Rafter, J. (1990). Principles of Building Economics, BSP Publishers, London.
Thompson, P. A. and Perry, J. G. (1992). Engineering Construction Risks. London: Thomas Telford.

Touran, A. (2003). Probabilistic Cost Estimating with Subjective Correlations. Journal of Construction Engineering and Management, 119(1), 58-71.

Williams, T. P. (2003). Predicting Final Cost for Competitively Bid Construction Projects Using Regression Models. International Journal of Project Management, 21, 593599.

Yeo, K. T. (1990). Risks, Classification of Estimates and Contingency Management. Journal of Management in Engineering 6(4): 458-470. 